than in Dionysius. Indeed, I love Plato in Iamblichus, I am full of admiration for him in Plotinus, I stand in awe of him in Dionysius [...]" (5). This letter, moreover, allows us to confirm that Ficino, like most of his contemporaries, believed that Dionysius had lived and taught prior to Iamblichus and Plotinus, exerting an influence on both.

Other curious and interesting elements can be found in the remaining missives. Letter 25, entirely dedicated to the concept that harmful ideas, like those presented in Orpheus's Hymns, must not be spread, contains-ironically enough-Ficino's translations of two such poems, accompanied by a reflection on Porphyry's On images, fragment 3. Ficino's choice of the first hymn, sometimes known as Palinode, is particularly meaningful, as it revolves entirely around the idea of merging all Olympian gods in one, thus suggestingaccording to the translators' notes-that the gods of the pagan tradition could co-exist and be incorporated within principles of monotheism, even in ancient Greek culture. Letter 30 and D deal with the nature of demons, and prefigure the publication of Ficino's On the Soul and Daemons, published in 1497 with Iamblichus's De mysteriis (Venice, Aldus Manutius). Extremely interesting is also letter 15, where Ficino addresses Giovanni Pico della Mirandola as a "true fisher of men" (17), guiding humanity to Christendom through Plato.

In conclusion, this new edition of Ficino's letters continues the positive trend of the past volumes, and posits itself as a precious instrument of research and an inspiring reference for Ficino scholars and Renaissance experts alike.

MARCO PIANA

McGill University

\title{
Garnier, Édith.
}

\section{Guillaume du Bellay, l'ange gardien de François $I^{e r}$.}

Paris : Éditions du félin, 2016. 428 p. ISBN 978-2-86645-835-5 (broché) $29 €$.

Spécialiste de l'histoire maritime et déjà auteur d'un ouvrage remarqué sur l'alliance impie conclue entre François ${ }^{\text {er }}$ et Soliman le Magnifique contre Charles Quint (2008, édition du félin, prix Diane Potier-Boès de l'Académie Française), Édith Garnier offre aujourd'hui à ses lecteur un excellent livre sur Guillaume du Bellay. Au fil de vingt-cinq chapitres bien équilibrés, l'auteur 
présente et explicite le rôle fondamental du seigneur de Langey auprès du souverain François $I^{\text {er }}$. "Brillant humaniste et défenseur opiniâtre des intérêts de la couronne de France " (7) comme l'écrit Édith Garnier en guise d'introduction, Guillaume du Bellay mérite assurément d'être mieux connu. Né en 1491, ce jeune noble voit le jour à l'aube d'une "ère nouvelle " (chapitre 1) avec l'avènement prochain en Europe de trois nouveaux souverains, Charles Quint dans le Saint-Empire romain germanique, François I ${ }^{\text {er }}$ en France et Henry VIII en Angleterre. À cette période d'expansion, « d'agrandissement » (17) des territoires, d'innovation aussi, correspond la vague de la Renaissance italienne, un bouillonnement intellectuel incroyable qui commence alors à toucher la France. Féru d'études latines, grand admirateur d'Érasme, Guillaume du Bellay participe pleinement à ce mouvement culturel. Il reçoit une éducation humaniste qui donne à l'art de l'éloquence, la rhétorique, une place privilégiée : du Bellay aura ainsi, comme le souligne bien Édith Garnier, cet atout d'être capable de construire un discours, d'analyser celui d'autrui et d'y répondre par une expression juste et précise tout en captant son auditoire. "Cette capacité à séduire les intelligences et entraîner les volontés par leur seule parole, était alors réservée à une petite minorité alors que le développement de la diplomatie, des échanges d'ambassadeurs (...) créait un besoin en individus pourvus de ces talents : Guillaume avait trouvé sa voie » (13). Infatigable, il se déplace beaucoup dans toute l'Europe et séjourne dans les grandes universités du temps, telles celles de Padoue, Pavie, Bologne, Ferrare ou Gênes. Grâce à sa vaste culture, il redonne de l'éclat à l'image du souverain français quelque peu écornée par ses ambitions expansionnistes dans la péninsule italienne.

De nombreux chapitres du volume sont également consacrés à la figure de Charles Quint et à ses velléités de domination sur l'Europe (chapitres II à VII notamment). L'auteur présente l'empereur comme un redoutable " chasseur », tandis que François I ${ }^{\text {er }}$ serait le « gibier " (91). Véritable cerveau de la politique anti-Habsbourg du roi de France, Guillaume combat sur tous les fronts contre Charles Quint, par l'épée et par la plume. Homme de guerre, orateur, propagandiste, pamphlétaire, diplomate officiel et officieux, il construit patiemment un service de renseignement à la hauteur de celui de l'Empereur. Charles Quint est loin de se douter que l'auteur de multiples pamphlets de propagande répandus en Allemagne est aussi celui qui ameute contre lui les puissances italiennes et tente d'empêcher le souverain pontife de se soumettre à ses conditions ! Langey est en déplacement incessant, sillonne l'Europe et ses 
palais, rencontre les plus puissants souverains du temps et négocie d'arrachepied, dans l'ombre, la politique européenne afin de servir les intérêts du roi français. Attiré par les esprits éclairés, il noue des liens forts, lors de ses séjours romains, avec les partisans de l'indépendance de l'Italie. L'auteur montre bien comment il entre ainsi dans l'intimité du florentin Filippo Strozzi, banquier immensément riche et familier des Médicis, mais aussi de Stefano Colonna, commandant de la garde suisse du pape, condottiere et grand érudit.

À l'intérieur même du royaume de France, il met en place une politique audacieuse et livre un combat acharné en faveur de la concorde religieuse. L'ouvrage met aussi en exergue combien l'érasmien du Bellay, proche des idées défendues par les évangéliques et par le cercle de Marguerite de Navarre, sœur de François I ${ }^{\text {er }}$, devient rapidement la bête noire des conservateurs catholiques comme des artisans de la contre-réforme. L'auteur dévoile également les heures sombres du règne de François $\mathrm{I}^{\mathrm{er}}$, les failles et les échecs des projets diplomatiques de Guillaume et de son frère Jean face aux initiatives des impériaux (340-342).

Édith Garnier suit son héros jusqu'à ses ultimes succès diplomatiques, ses grandes déceptions lorsque les « lumières s'éteignent », suivis de son décès dans la décennie 1540, période marquée entre autre par la mise à mort de Thomas More par le roi de l'âge d'or, Henri VIII. Les trois derniers chapitres évoquent les derniers combats et les dernières utopies, puis le «dernier voyage » (405) de Guillaume qui décède en 1543. Grand admirateur de l'éminent humaniste et de l'habile diplomate, Rabelais rendra hommage à de multiples reprises au seigneur de Langey (410).

Figure incontournable de la Renaissance finissante, Guillaume du Bellay offre l'occasion de découvrir ou redécouvrir la face cachée de la Renaissance, celle décrite par Machiavel, cet univers de la diplomatie parallèle, de l'intrigue, des mensonges, des trahisons et des renversements d'alliances. Si on peut regretter le faible appareil critique du volume, il demeure que cet ouvrage est solide, très documenté et construit sur des sources primaires détaillées en fin d'introduction (9). Excellent travail, précis et stimulant, ce beau livre donne envie de poursuivre, par la lecture de sa correspondance notamment, la découverte de Guillaume du Bellay, véritable ange gardien de François I ${ }^{\mathrm{er}}$.

MARIE BARRAL-BARON

Université de Franche-Comté 